\title{
Seismic load considerations in the design of underground structures for hydropower projects in the Himalayan region
}

\author{
TK Sivarajan \\ Central Water Commission, \\ New Delhi, India \\ tksivarajan@gmail.com
}

\begin{abstract}
Generally, during earthquake events, underground structures have experienced a lower rate of damage than surface structures. Nevertheless,some underground structures registered significant damages in large earthquakes (the 1995 Kobe, Japan, the 1999 Chi-Chi, Taiwan, the 1999 Turkey, the 2008 China). Due to seismic events and consequent propagation of elastic waves, the underground structures experience dynamic forces and moments that may affect its stability, depending on the size of the structure, strength of rock, depth of overburden, stiffness of rock support system etc. In this paper, numerical analysis using Phase2 software (2D FEM) has been used for investigating the effects of seismicity on tunnelsin weak and competent rock. Influence of rock mass quality $(Q)$ on the axial force developed in the tunnel lining due to dynamic loading has also been examined. The study shows that the impact of seismic loading on tunnel supports are more significant in weak rocks than in competent rock mass. The results obtained from this study can serve as useful tools for design of support system for tunnels and caverns in areas susceptible to earthquake, especially in the Himalayan region, where many new hydropower projects are being planned.
\end{abstract}

Keywords-Seismic Load, Underground Structures, Hydropower Projects, Himalayan Region

\section{INTRODUCTION}

The underground structures are less susceptible to damage due to earthquakes thansurface structures due to various factors such as reduction in ground motion with depth and consequent reduction in seismic coefficient, increased modulus with depth, small excavation dimension with respect to the much larger seismic wave length, etc. The behaviour of underground structures such as tunnels and caverns is strikingly different from surface structures during an earthquake event. While inertia of the structures plays a dominant role for surface structures, the response of the confining rock mass has significant influence on the behaviour of tunnels and caverns. The main parameters which can influence the damage to underground structures due to seismicity are magnitude of earthquake, distance to epicentre, Peak Ground Acceleration (PGA), geology, Rock Mass Quality, overburden, age of tunnel, depth of the tunnel, location and orientation of any faults, in-situ stress, type of support system and purpose of the tunnel.There are many examples of severe damages during large earthquakes reported in literatures. Significant among them are:1995 Kobe, Japan; the 1999 Chi-Chi, Taiwan; the 1999 Kocaeli, Turkey; the 2004 Niigata, Japan, and the 2008Wenchuan, China.

The earthquake-induced damages mainly include: (a) Slope failure at portals,(b) displacement of tunnels due to fault slip and (c) damage due to ground shaking resulting in cracks in the lining and spalling of the lining.The main purpose of this paper is to analyze the impact of earthquakes on tunnel supports by numerical modelling using Phase $^{2}$ software which has the facility to model seismic loads through pseudo-static approach. The type of rock mass (Elastic or Elastic - plastic), tunnel dimension and rock mass quality have been considered and the increase in the axial force generated in the support (lining) for various conditions has been computed. Due the complex nature of influence of depth of tunnel on the seismic effects, this study has not been done at present. Also it may be noted that most of the earthquake damages occur at shallow depths.Three types of deformations are possible in underground structures due to seismic loading. These are:(i) Axial compression and extension (ii) longitudinal bending and (iii) ovaling / racking. These are pictorially shown in Fig. 1below:

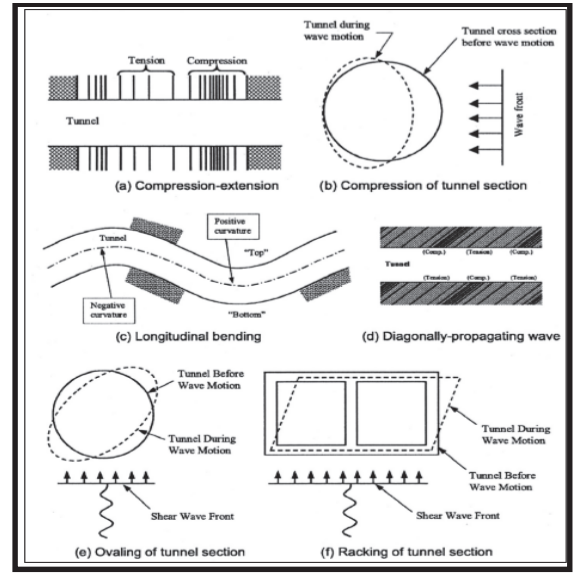

Fig1. Types of deformations possible in underground structures due to seismic loading 


\section{NUMERICAL ANALYSIS FOR TUNNELS UNDER EARTHQUAKE LOADING}

For the analysis and design of underground excavation including rock support, the finite element modelling (FEM) program Phase 2 from Rocscience Inc. is commonly used.The software has the facility to carryout dynamic analysis of underground structures due to earthquake loading using the pseudo-static seismic analysis procedure. The seismic coefficients for the horizontal and/or vertical directions are specified depending on the characteristics of the earthquake and depth of the excavation. The seismic coefficients are dimensionless coefficients which represent the (maximum) earthquake acceleration as a fraction of the acceleration due to gravity. Typical values are in the range of 0.1 to 0.3 .

When a seismic coefficient is defined,an additional Body Force will be applied to each finite element in the mesh. The Seismic Force is the product of Seismic Coefficient and the Body Force (due to gravity). The body force (due to gravity) is simply the self-weight of a finite element. The seismic body force is vectorially added to the (downward) body force which exists due to gravity, to obtain the total body force acting on the element. While carrying out the analysis with seismic loading, multiple analysis using different combinations and directions of horizontal and vertical seismic coefficients are applied in order to study the effect of seismic force on the analysis results. The magnitude of vertical acceleration is usually lower than that of the horizontal acceleration. It generally varies from one quarter to one-fifth of the horizontal acceleration. However, some research papers show that it can be of the order of onehalf or even equal to the horizontal acceleration.

Seismic analysis on tunnels with different combinations of horizontal and vertical seismic coefficients shows that maximum stresses are produced on the tunnel periphery when the vertical seismic coefficient is acting downwards, in the same direction as that of gravitational force. Hence for the studies presented here, a horizontal seismic coefficient of 0.3 and a downward vertical seismic coefficient of -0.2 (negative for downward direction) have been adopted. The in-situ stress (static load) adopted is hydrostatic stress field due to gravity.

The effect of seismic loading on competent (elastic) and weak (elastic - plastic) rock mass has been investigated by considering a circular tunnel of $10.0 \mathrm{~m}$ diameter excavated at a shallow depth of $70.0 \mathrm{~m}$. The following rock mass parameters have been considered:For an elastic model of a particular rock mass type, the slope of thestress-strain curve is proportional to the specified deformation modulus, but the rock mass neverreaches failure point, and continues to behave as elastic materials for all stress levels. Also weaker rock masses are known to behave aselastic-perfectlyplastic materials.

The results of various studies are given in the following: The maximum axial force developed in the shotcrete lining for elastic rock mass (competent) for static and earthquake (EQ) loading are shown in Fig.2, Fig.3 and Fig.4. The maximum axial force developed in the shotcrete lining for
Elastic- perfectly Plastic rock mass (weak) for static and earthquake (EQ) loading are shown in Fig.5, Fig.6 and Fig.7.The maximum axial force in the lining under EQ loading for the Elastic rock mass and Elastic- perfectly Plastic rock mass are shown in Fig. 8.The maximum axial force developed in the lining for the elastic and elasticperfectly plastic cases under static and earthquake (EQ) loading are shown in Table I.

It can be seen from the above that the maximum axial force increases by about $37 \%$ for the elastic rock mass, when the seismic loads are applied. It has been increased by about $51 \%$ for the elastic- perfectly plastic rock mass. This shows the significant increase of load in the support system due to the dynamic force by earthquake, in the case of weak rocks in comparison with competent rock mass. It may be noted that these results are for a set of parameters assumed and actual increase in axial force depends on the realistic parameters of the underground structure.

In order to examine the influence of size of tunnels on the force generated in the lining due to earthquake loading, different tunnel sizes varying from $5 \mathrm{~m}$ dia. to $10 \mathrm{~m}$ dia. have been considered. The depth of the excavation has been kept at $70 \mathrm{~m}$ from the surface and the rock mass parameters have been adopted same as the previous case for the elastic and elastic-perfectly plastic rock types. The results are shown in Table- II.The maximum axial force in the lining under static and seismic loading is graphically shown in Fig.9. The percentage increase in the maximum axial force for static and seismic loading is shown in Fig 10.The percentage increase in maximum axial load in the lining due to seismic load for elastic rock and elastic-perfectly plastic rock are shown in Fig 10.0 above. It can be seen that there is no significant variation in the case of elastic rock. However, there is $44 \%$ to $51 \%$ increase, when the tunnel dia. is increased from $5.0 \mathrm{~m}$ to $10.0 \mathrm{~m}$. in case of elastic- plastic rock.

TABLE-I

\begin{tabular}{|l|r|l|l|c|c|c|}
\hline & \multicolumn{3}{|c|}{ Elastic rock } & \multicolumn{3}{c|}{ Elastic- plastic rock } \\
\hline & Stati & & \multicolumn{1}{c|}{$\%$} & STA & & \multicolumn{1}{c|}{$\%$} \\
& $\mathrm{c}$ & EQ & Increase & TIC & EQ & Increase \\
\hline Maximum axial & 0.60 & 0.82 & & 0.74 & 1.1 & \\
force (MN) & 258 & 553 & 36.99 & 047 & 198 & 51.22 \\
\hline
\end{tabular}

TABLE-II

\begin{tabular}{|c|c|c|c|c|c|c|}
\hline \multirow[b]{3}{*}{$\begin{array}{l}\text { Tunnel } \\
\text { Dia, (m) }\end{array}$} & \multicolumn{3}{|c|}{ Elastic rock } & \multicolumn{3}{|c|}{ Elastic- plastic rock } \\
\hline & \multicolumn{3}{|c|}{ Maximum axial force,(MN) } & \multicolumn{3}{|c|}{$\begin{array}{l}\text { Maximum axial force, } \\
\text { (MN) }\end{array}$} \\
\hline & Static & EQ & $\begin{array}{c}\% \\
\text { Increase }\end{array}$ & Static & EQ & $\begin{array}{l}\text { Increas } \\
\text { e (\%) }\end{array}$ \\
\hline 5 & 0.56 & 0.76 & 36.46 & 0.63 & 0.91 & 44.39 \\
\hline 6 & 0.57 & 0.78 & 36.44 & 0.66 & 0.96 & 46.16 \\
\hline 7 & 0.58 & 0.79 & 36.76 & 0.68 & 1.01 & 47.02 \\
\hline 8 & 0.59 & 0.80 & 36.85 & 0.70 & 1.05 & 49.35 \\
\hline 9 & 0.59 & 0.81 & 36.927 & 0.72 & 1.09 & 50.00 \\
\hline 10 & 0.60216 & $\begin{array}{r}0.82 \\
543 \\
\end{array}$ & 37.07 & 0.74 & 1.11 & 51.02 \\
\hline
\end{tabular}


The axial force developed in the lining under static loading and seismic loading conditions have been examined for two different values of rock mass quality $\mathrm{Q}$, for very poor rock (average $\mathrm{Q}=0.55$ ) and for good rock (average $\mathrm{Q}=25)$. The diameter of the tunnel is $8.0 \mathrm{~m}$ and the depth of excavation is $70 \mathrm{~m}$. The same horizontal seismic coefficient of 0.3 and a downward vertical seismic coefficient of -0.2 have been adopted.

The rock mass deformation modulus corresponding to these $\mathrm{Q}$ values have been computed using the formula $E m=10$ Qc (1/3), where Qc=Q. sigma-c /100 (as per Barton, 2014). The value of sigma-c has been taken as $100 \mathrm{MPa}$. The other parameters have been assumed as shown in the Table III.

The analyses have been done for elastic and elastic perfectly plastic rock types. The maximum axial force in the shotcrete lining for different values of $\mathrm{Q}$ are given in the Table-IV: The maximum axial force in the shotcrete lining for different values of Q are graphically shown in Fig. 13. The phase 2 results for the static and seismic loading for elastic- perfectly plastic tunnel dia. $5.0 \mathrm{~m}$ and $10.0 \mathrm{~m}$ are shown in Fig.11 and Fig.12. The maximum axial force for $\mathrm{Q}=0.55$, elastic rock is shown in Fig. 14 (a) and 14 (b) and elastic. plastic rock is shown in Fig.15 (a) and 15 (b).From the above it is observed that the maximum axial force due to seismic load is increased by twice in the case of very poor rock $(\mathrm{Q}=0.55)$ while there is no increase in the case of good $\operatorname{rock}(\mathrm{Q}=25)$.

\section{TABLE-III}

\begin{tabular}{|l|l|l|}
\hline Rock mass parameters & $\begin{array}{c}\text { Very poor rock } \\
\mathbf{Q}=\mathbf{0 . 5 5}\end{array}$ & $\begin{array}{c}\text { Good rock } \\
\mathbf{Q}=\mathbf{2 5}\end{array}$ \\
\hline Deformation modulus $\mathbf{E}(\mathrm{GPa})$ & 8.19 & 29.24 \\
\hline Poisson's ratio $\boldsymbol{\mu}$ & 0.25 & 0.25 \\
\hline Tensile strength $(\mathrm{MPa})$ & 0.02 & 0.02 \\
\hline Peak friction angle $\phi_{\mathbf{p}}($ degrees $)$ & 15 & 40 \\
\hline Peak cohesion $\mathbf{C}_{\mathbf{p}}(\mathrm{MPa})$ & 1.0 & 3.5 \\
\hline Dilation angle $($ degrees $)$ & 0 & 0 \\
\hline Residual friction angle $\phi_{\mathbf{r}}($ degrees $)$ & 15 & 30 \\
\hline Residual cohesion $\mathbf{C}_{\mathbf{r}}(\mathrm{MPa})$ & 0.1 & 0.1 \\
\hline
\end{tabular}

TABLE-IV

\begin{tabular}{|l|r|r|l|r|r|l|}
\hline & \multicolumn{3}{|c|}{ Elastic rock } & \multicolumn{3}{c|}{ Elastic- plastic rock } \\
\hline & Static & EQ & $\begin{array}{l}\text { \% } \\
\text { Increase }\end{array}$ & Static & EQ & $\begin{array}{l}\% \\
\text { Increase }\end{array}$ \\
\hline $\begin{array}{l}\text { Maximum } \\
\text { axial force } \\
\text { For q=0.55 }\end{array}$ & 0.82 & 1.1 & 36.0 & 1.5 & 2.1 & 37.012 \\
\hline $\begin{array}{l}\text { Maximum } \\
\text { axial force } \\
\text { For q=25 }\end{array}$ & 0.24 & 0.3 & 38.2 & 0.2 & 0.3 & 40.8 \\
\hline
\end{tabular}

When both the static and seismic loading is considered, the change in maximum axial force is from $0.24 \mathrm{MN}$ to $0.35 \mathrm{MN}(1.4$ times) for good rock and from $0.82 \mathrm{MN}$ to 2.11 MN (2.6 times) in the case of very poor rock. This clearly shows that the impact of seismic loading is significant in the case of poor and very poor rock mass.

\section{HYDROPOWER DEVELOPMENT IN THE HIMALAYAN REGION}

The availability of a large volume of water combined with suitable slopes offers tremendous potential for the hydropower development in the Himalayan region. The Indian Himalayan region accounts for approximately $18 \%$ of India's total geographical area and own more than $75 \%$ (about 1,17,139 MW) of total exploitable hydro potential.

However, the Himalayan region experience many difficulties during tunnelling posed by high level of seismicity, geological features like thrust zones, shear zones, folded rock sequence, in-situ stresses, rock cover, ingress of water, geothermal gradient, ingress of gases etc. The region has been rocked by several damaging earthquakes, Kangra EQ (1905 - magnitude 7.8), Bajang Dharchula EQ(1980-magnitude 6.1), Uttarkashi EQ(1991magnitude 6.8), recent Nepal EQ(2015-magnitude7.8) etc.

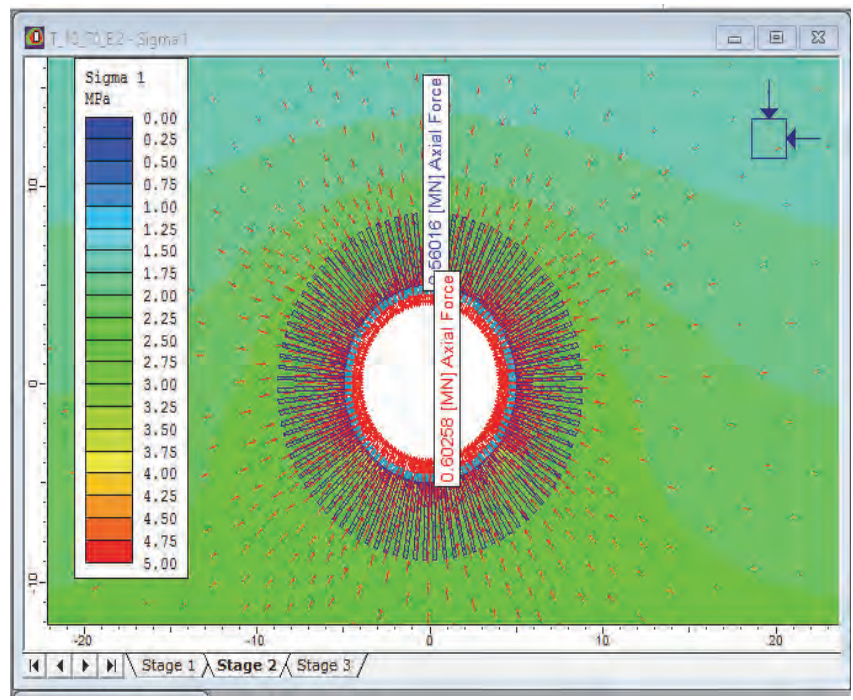

Fig .2 (a) Static - Maximum axial force in the lining

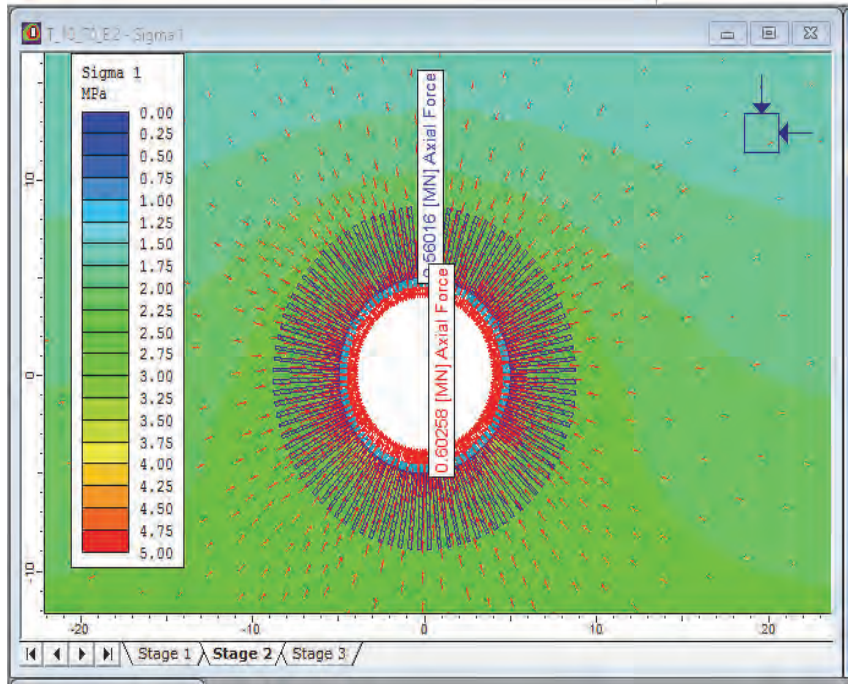

Fig .2 (b) EQ - Maximum axial force in the lining 


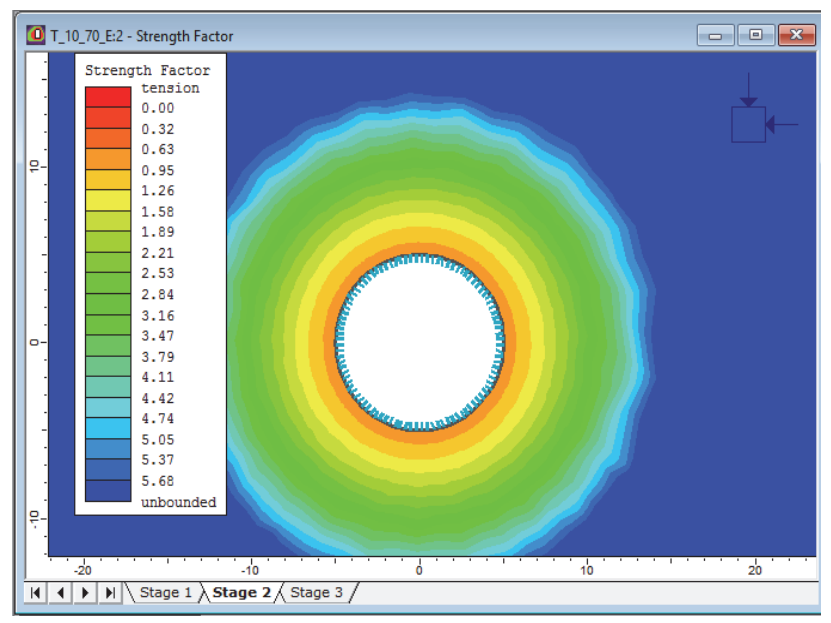

Fig .3 (a) StaticStrength Factor

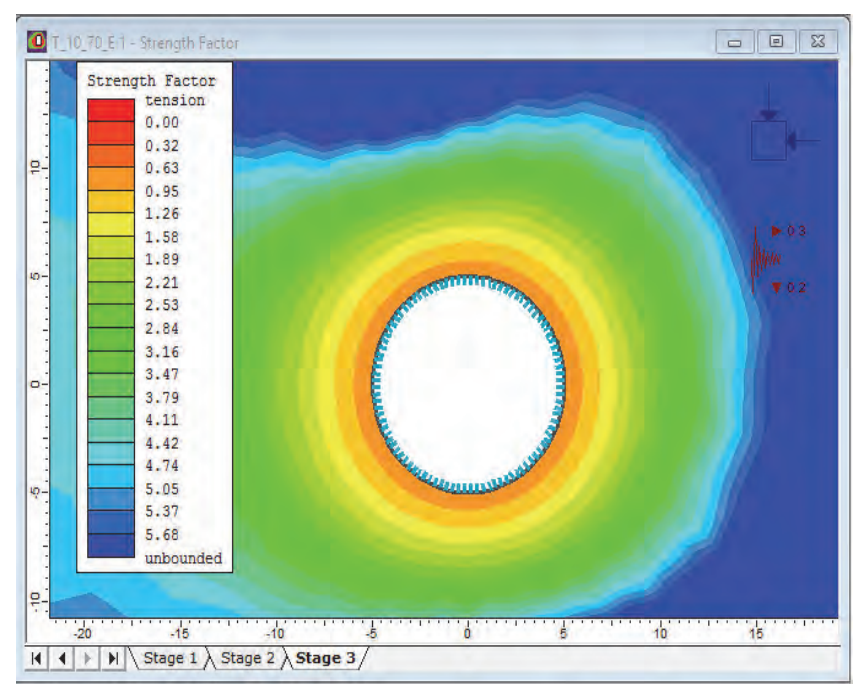

Fig .3 (b) EQ - Strength Factor

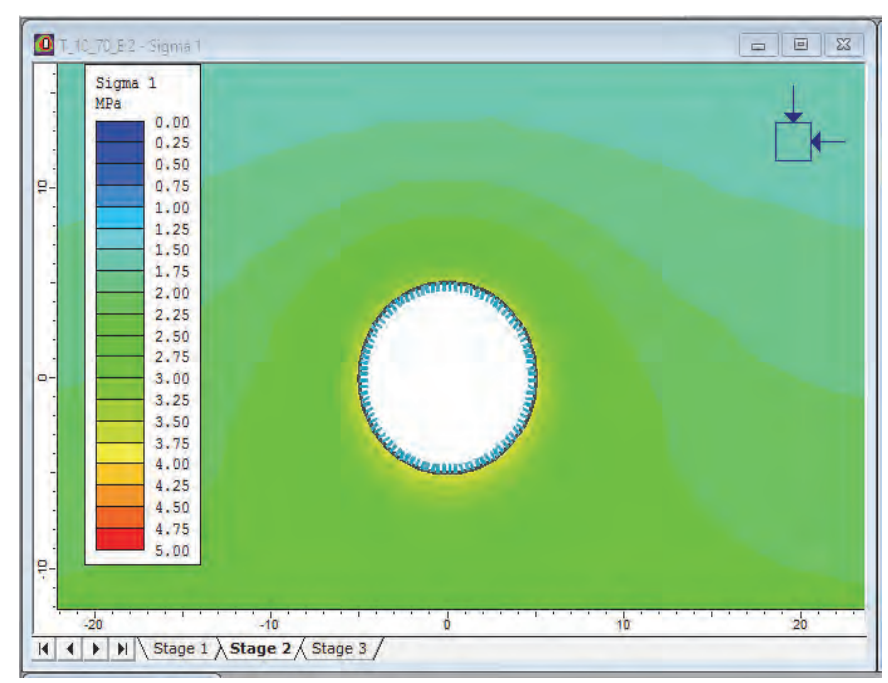

Fig .4 (a) StaticMajor principal stress (sigma 1)

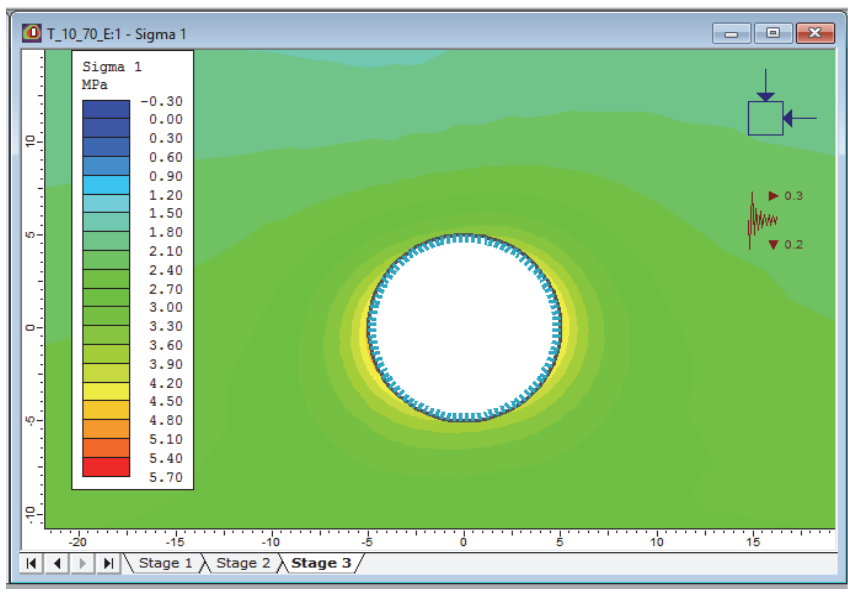

Fig .4 (b) EQMajor principal stress (Sigma 1)

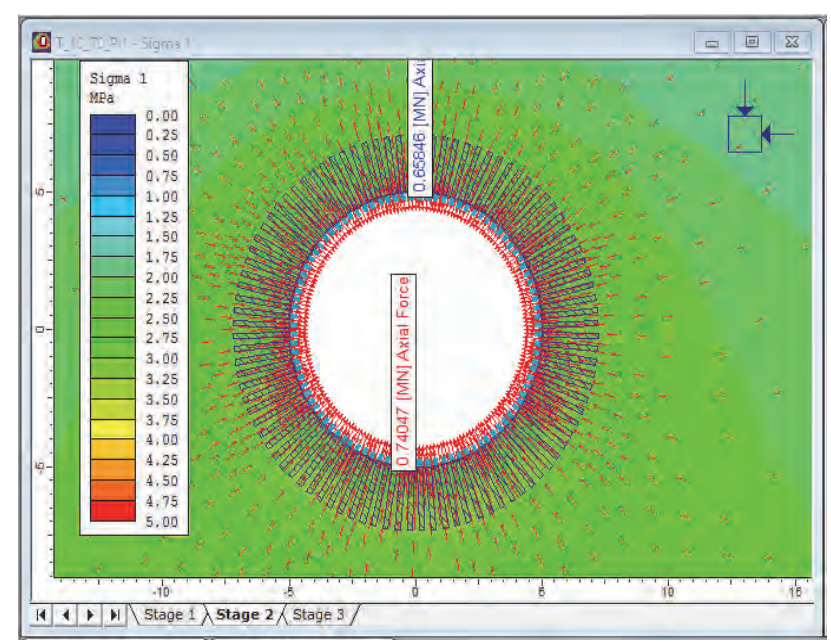

Fig .5 (a) StaticMaximum axial force

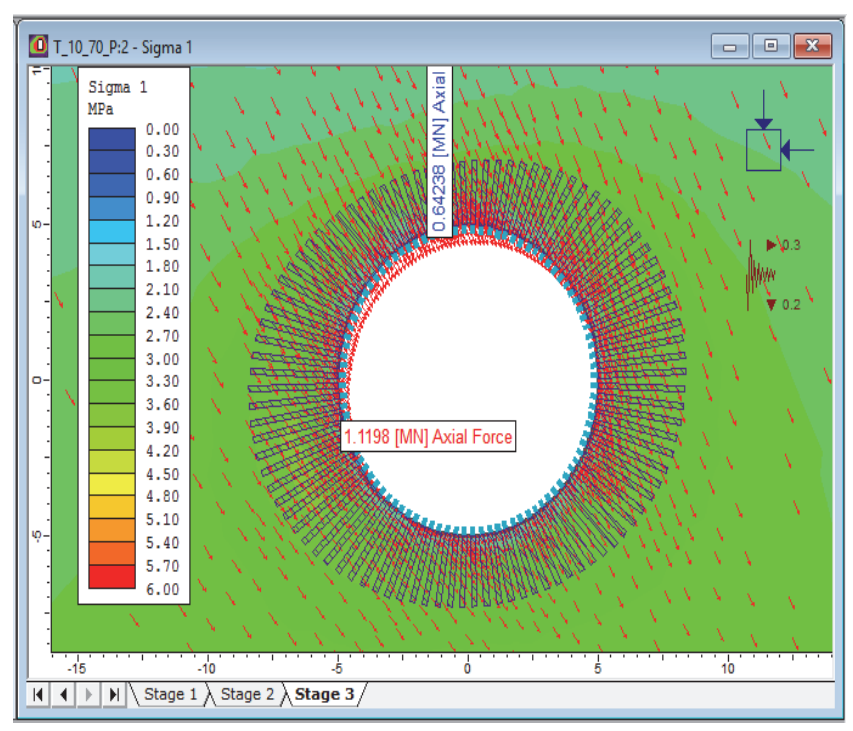

Fig .5 (b) EQMaximum axial force 


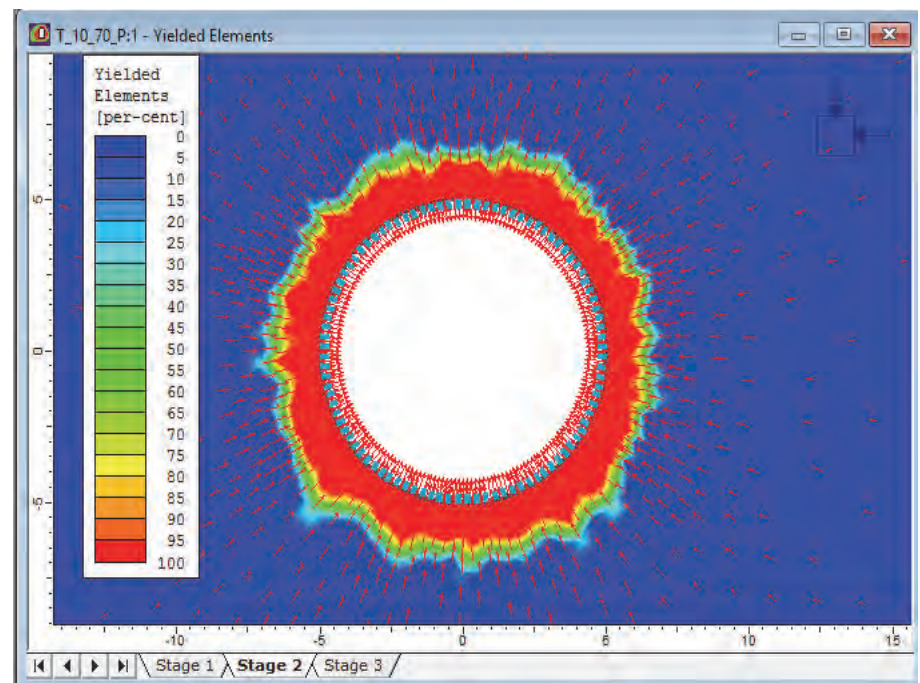

Fig .6 (a) StaticYielded Elements

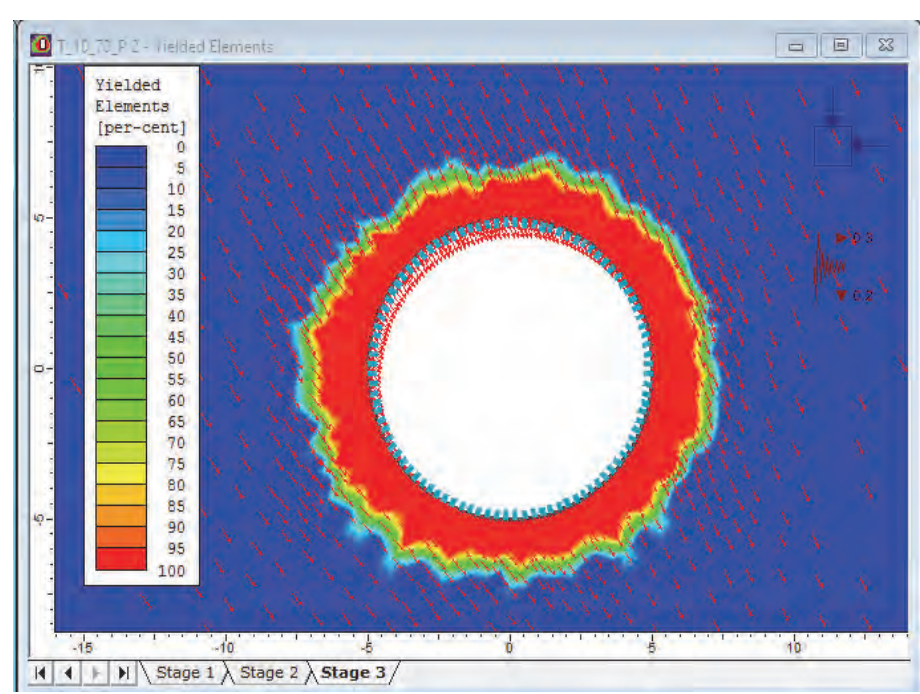

Fig .6 (b)EQYielded Elements

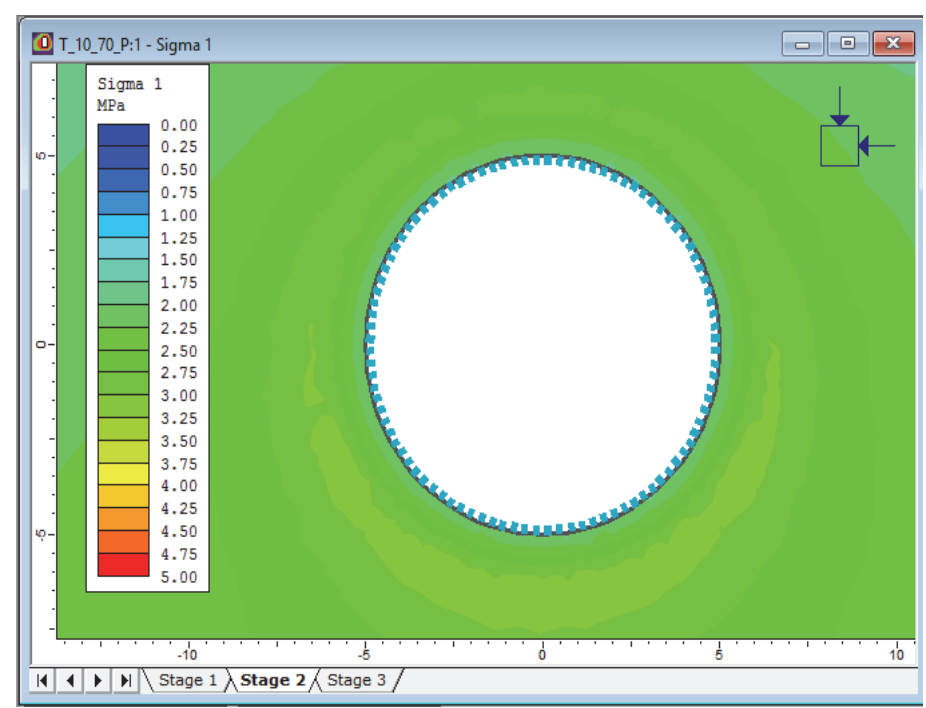

Fig .7 (a) StaticMajor principal stress (sigma 1)

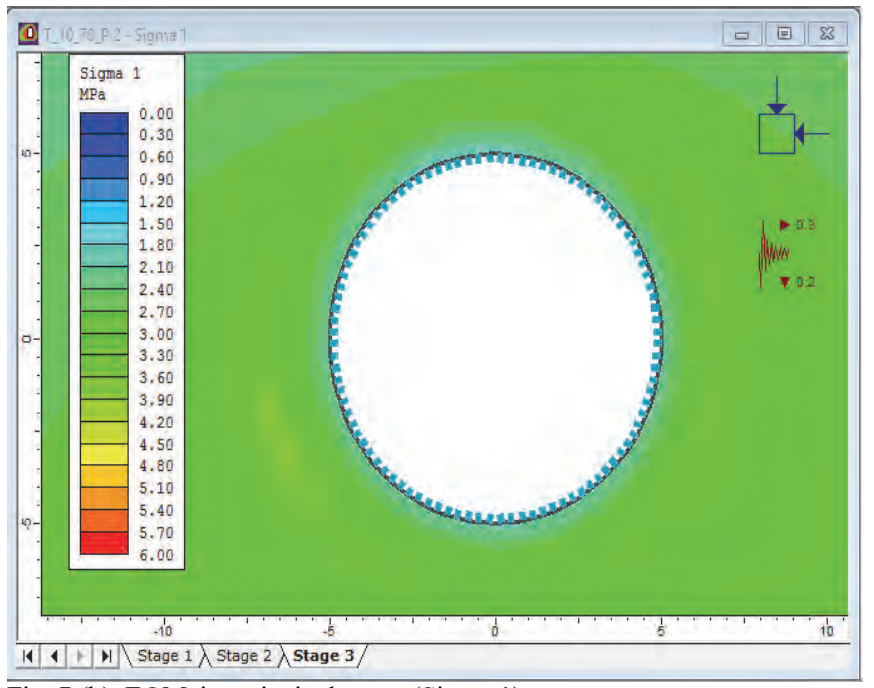

Fig.7 (b) EQMajor principal stress (Sigma 1)

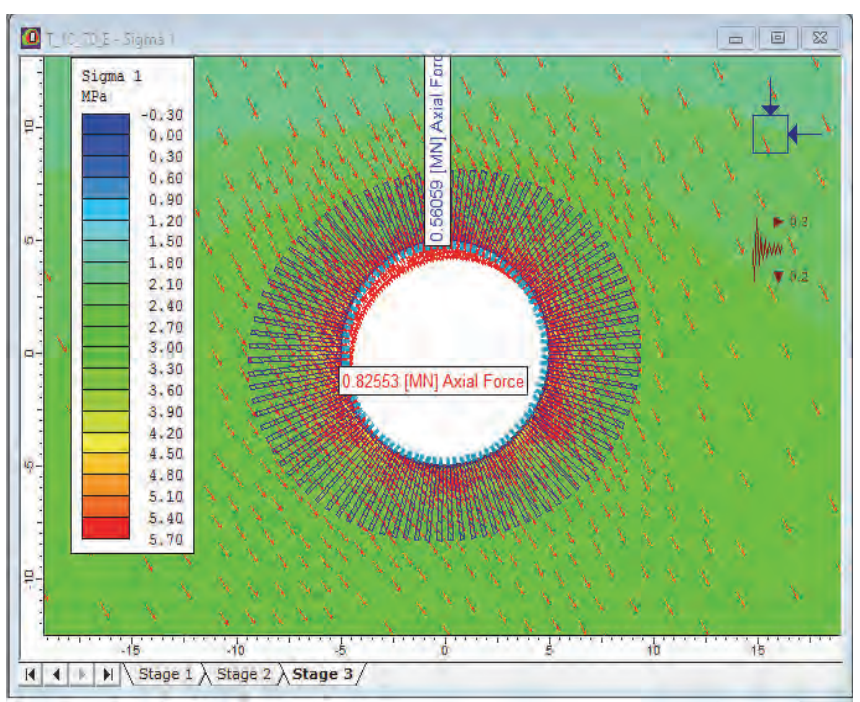

Fig .8 (a)Elastic maximum axial force

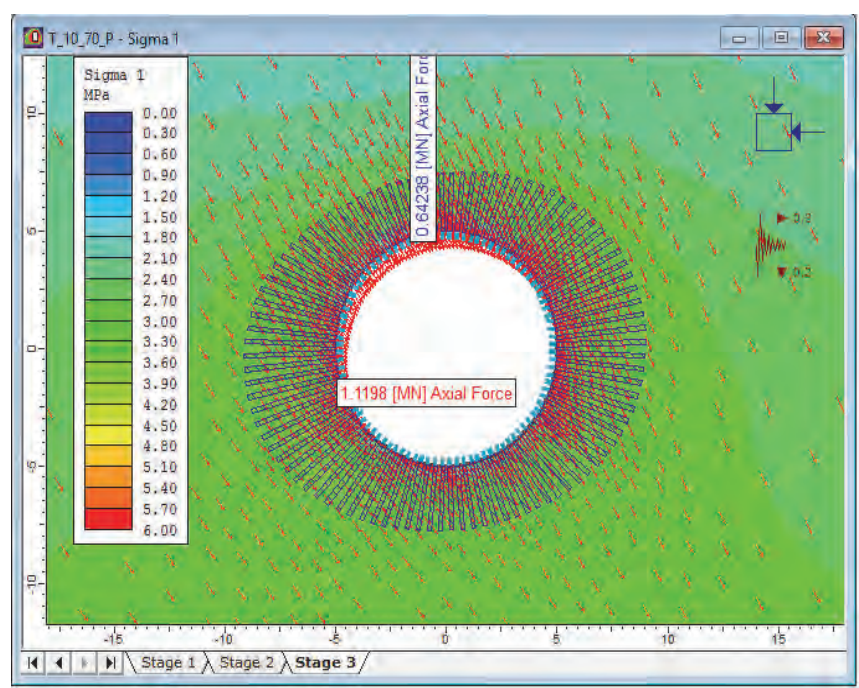

Fig .8 (b) Elastic Perfectly Plastic - maximum axial force 


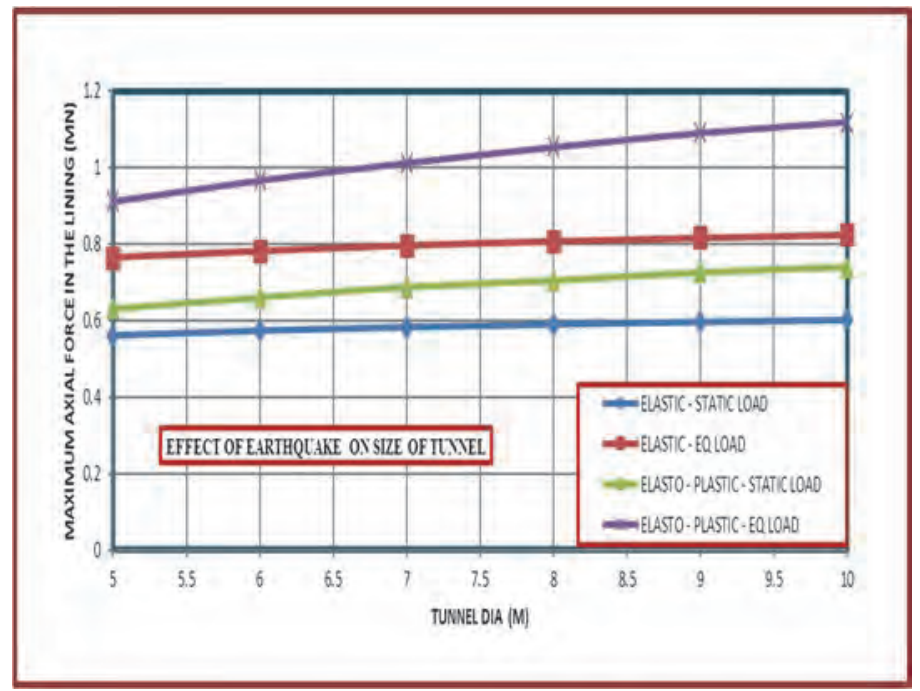

Fig 9. - maximum axial force in the lining for different tunnel sizes

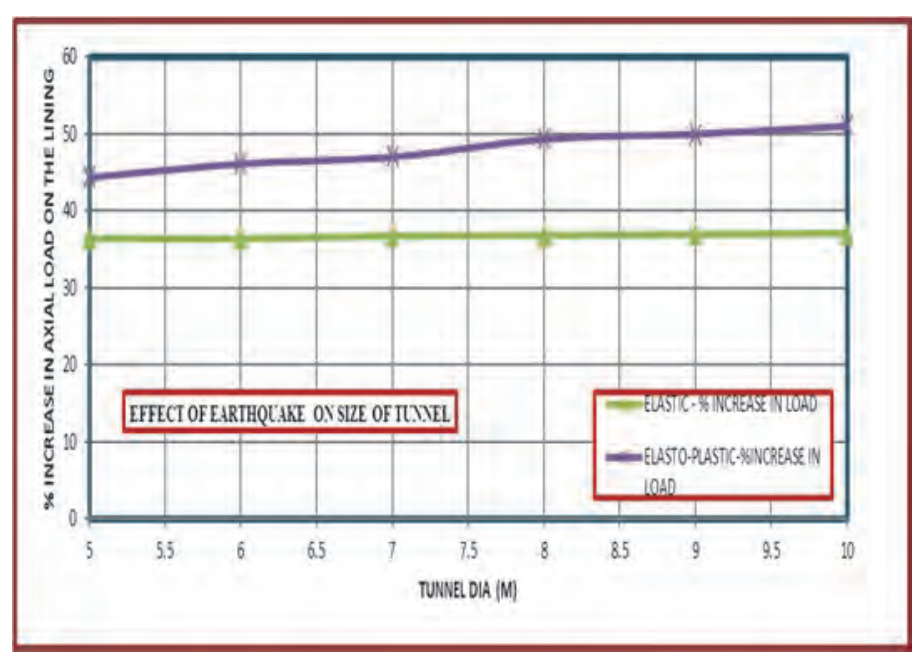

Fig $10.0 \%$ increase in the maximum axial force in the lining for different tunnel sizes

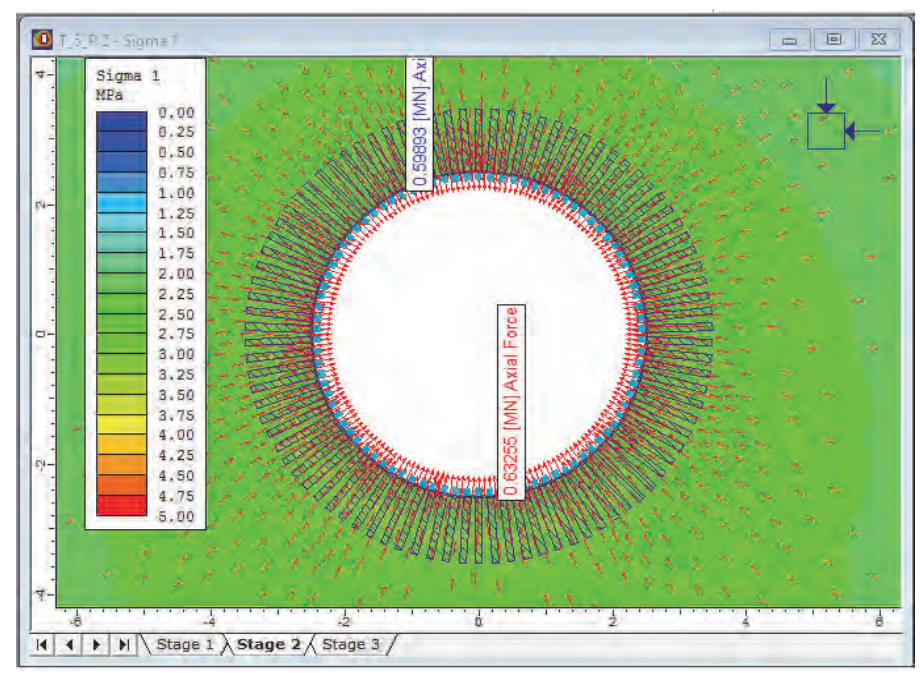

Fig.11(a)-5.0m dia - Max. axial load for static load

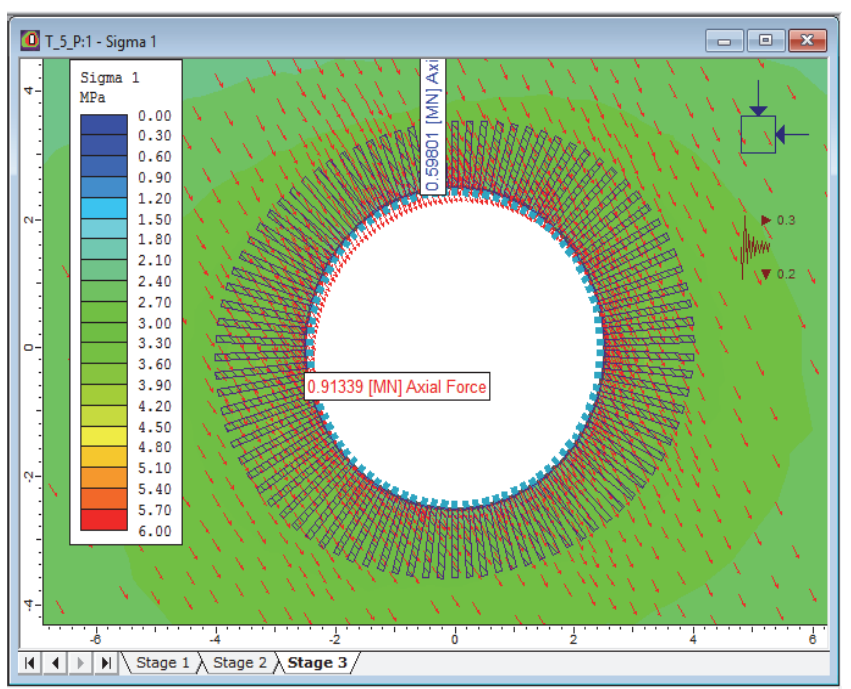

Fig.11(b)- 5.0m dia - Max. axial load for EQ load

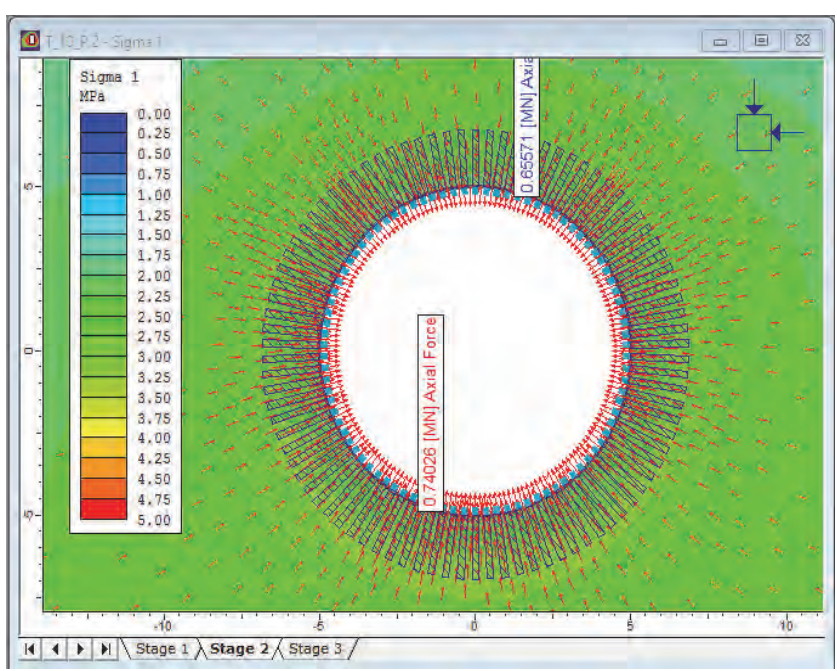

Fig.12(a) - 10.0m dia - Max. axial load for static load

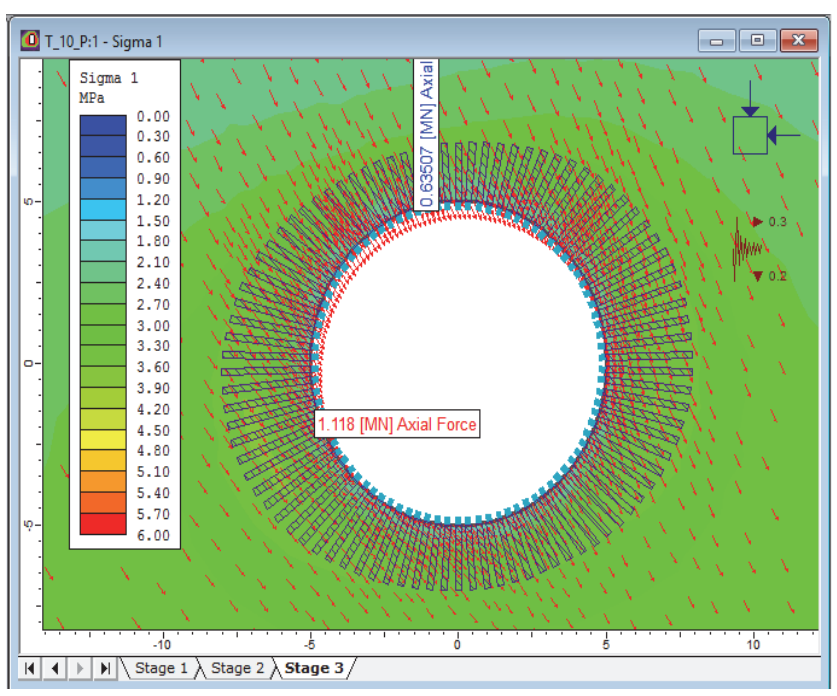

Fig.12 (b) - 10.0m dia - Max. axial load for EQ load 


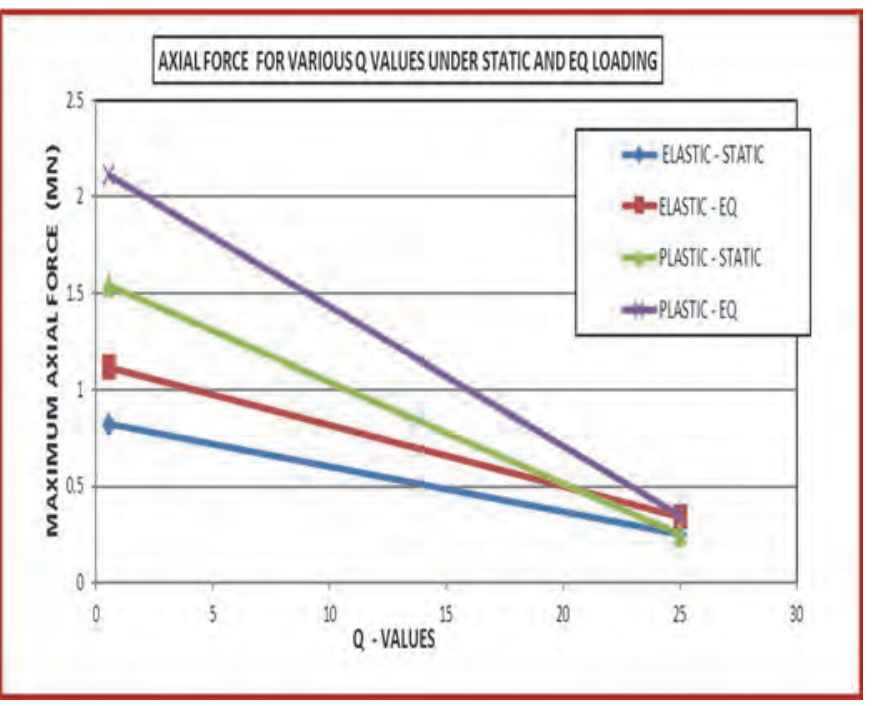

Fig 13.0- maximum axial force for different values of Q

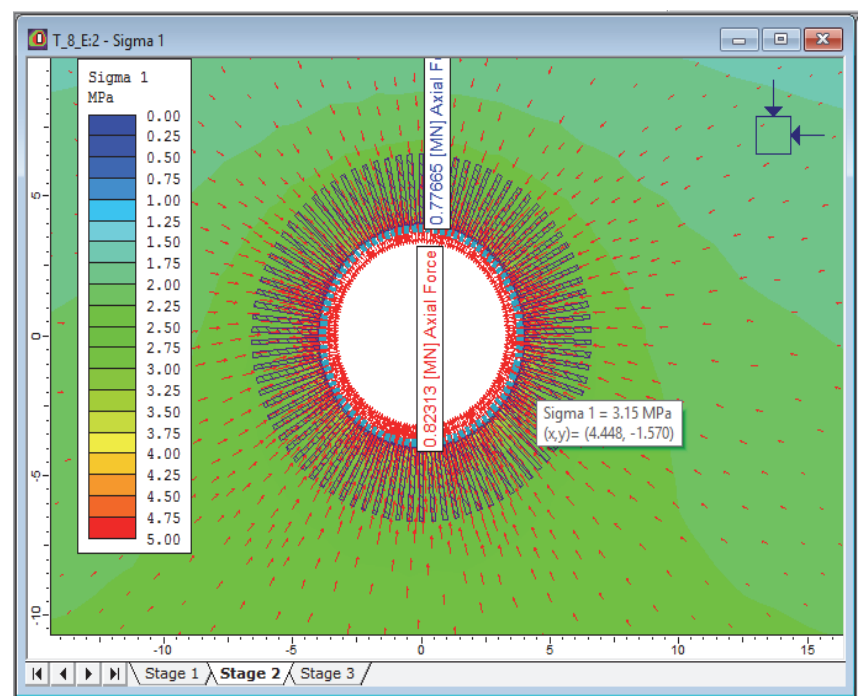

Fig 14 (a)- $Q=0.55$ Elastic - static load

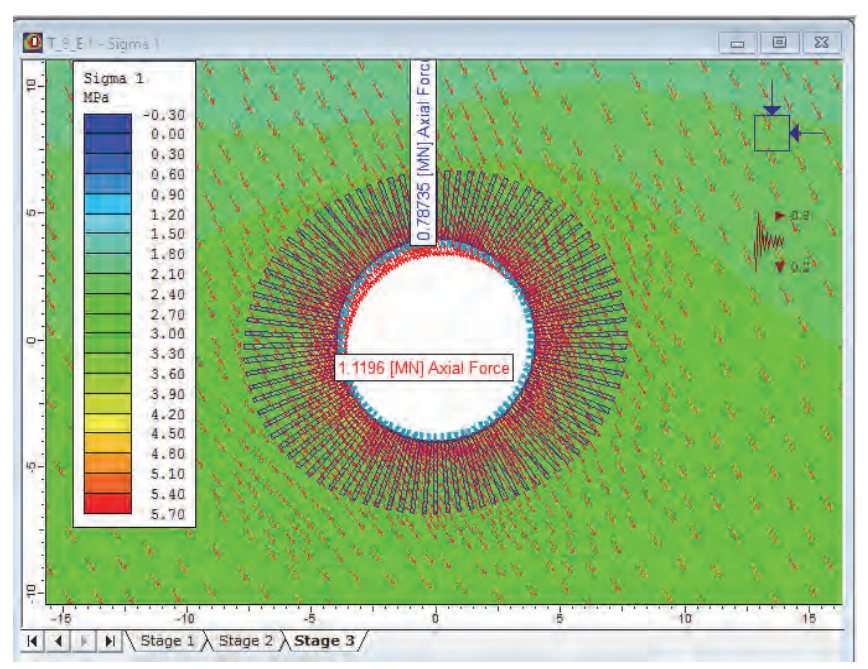

Fig 14 (b)- $Q=0.55$ Elastic - EQ load

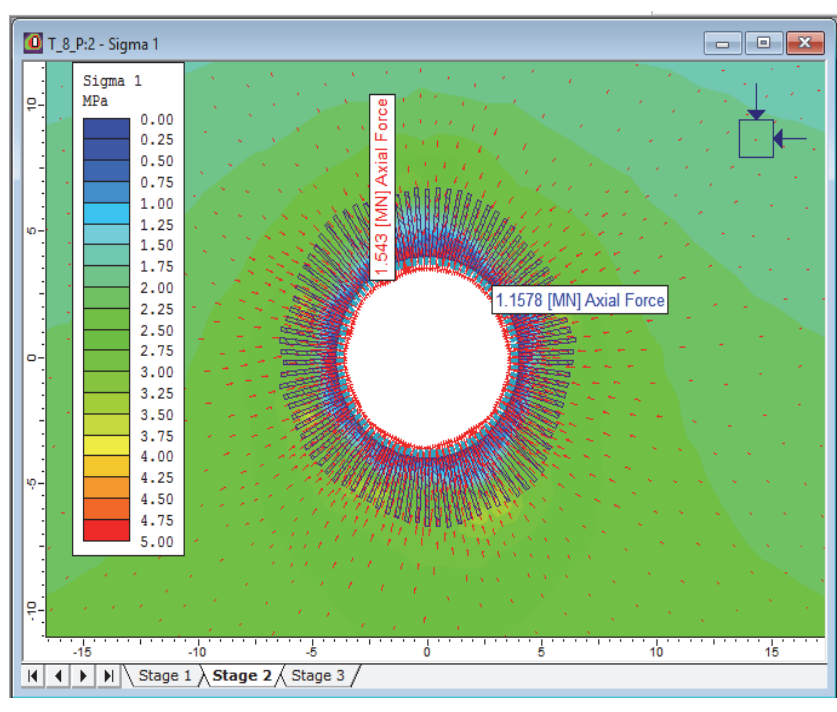

Fig 15 (a)- $\mathrm{Q}=0.55$ Plastic - static load

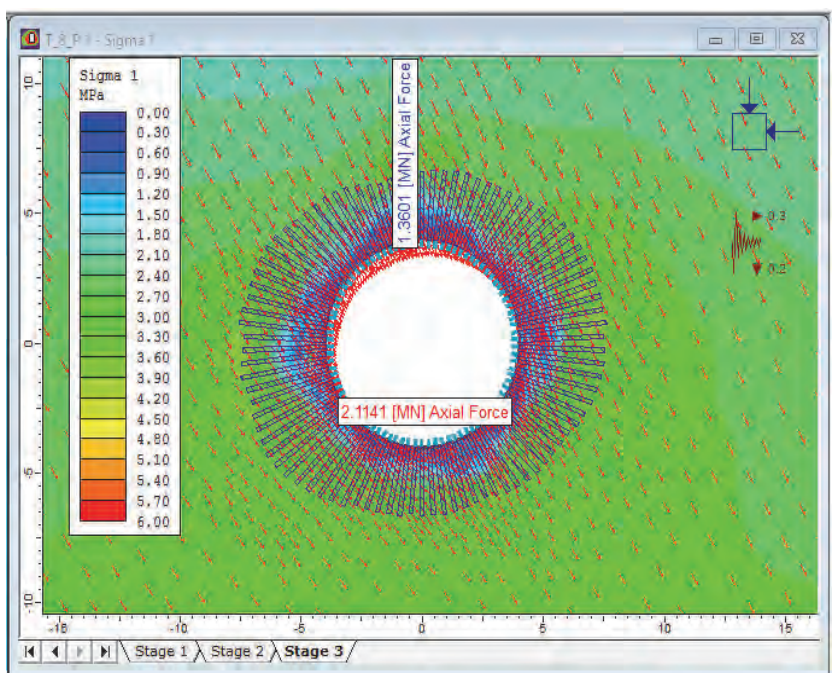

Fig 15 (b)- Q=0.55 Plastic - EQ load

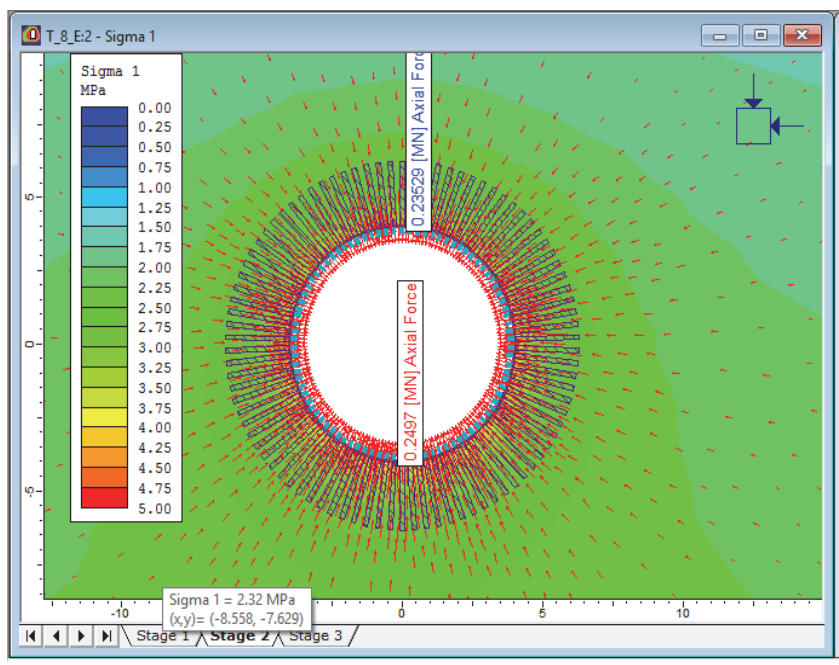

Fig 16 (a)- Q=25 Elastic - static load 


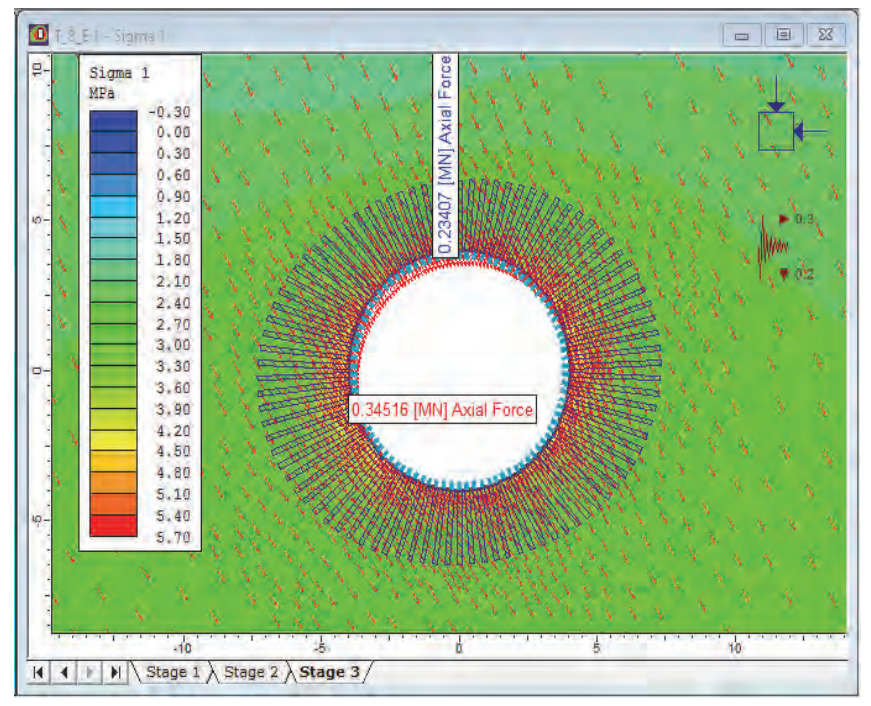

Fig 16 (b)- Q=25 Elastic - EQ load

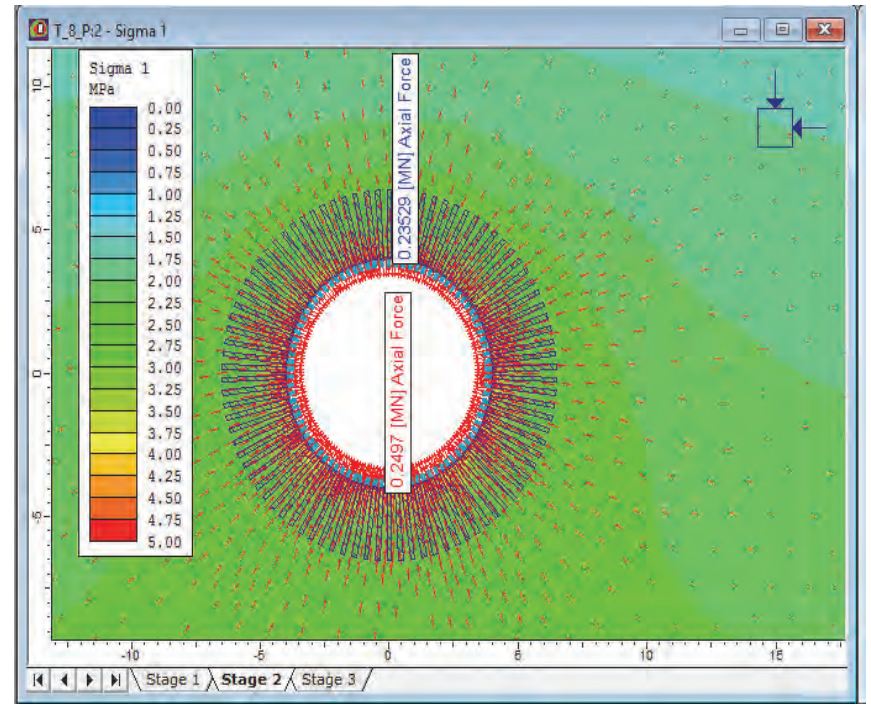

Fig 17 (a)- Q=25 Plastic- static load

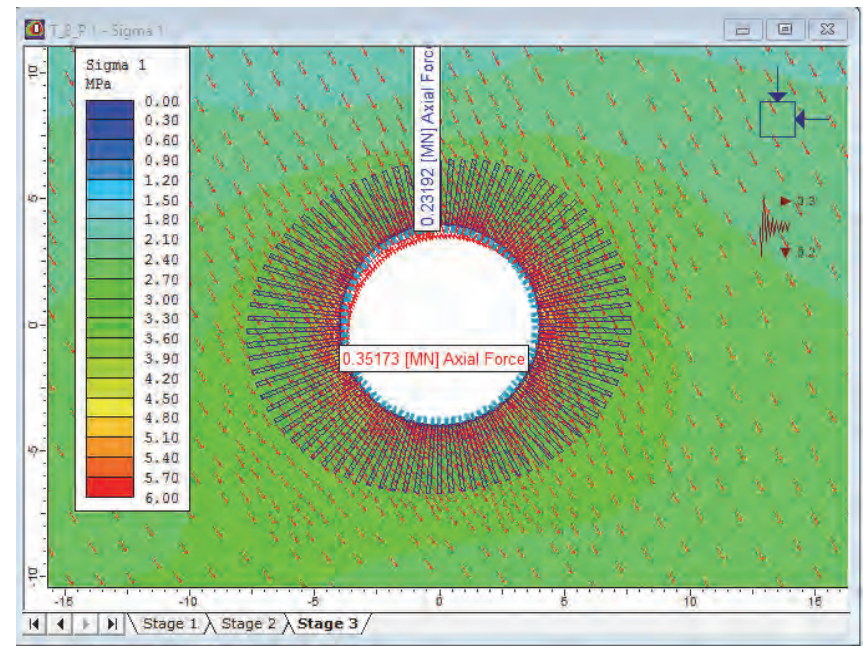

Fig 17 (b)- $\mathrm{Q}=25$ Plastic - EQ load
The impact of earthquakes on tunnels and underground structures are required to be studied in detail so that adequate safety margins are provided in the design of support system and lining. Since many factors including the size and depth of excavation, rock mass parameters, appropriate seismic coefficient in horizontal and vertical directions etc. are influencing the computation of force generated due to seismic load, numerical modelling with different combinations of parameters can be adopted.The maximum axial force for $\mathrm{Q}=25$, elastic rock is shown in Fig. 16 (a) and 16 (b) and elastic - plastic rock is shown in Fig. 17 (a) and 17 (b).

\section{CONCLUSIONS}

- Analysis of the impact of seismic loading on tunnel support (lining) has been carried out by numerical modelling using Phase $^{2}$ software which has the facility to model seismic loads through pseudo-static approach. Elastic and Elastic -perfectlyPlastic rock types have been considered with different tunnel sizes. The axial force generated in the support (lining) for two different values of rock mass quality $\mathrm{Q}$ have also been studied under static and seismic loading conditions.

- From the above studies it is found that under the seismic loading, the maximum axial force developed in the shotcrete lining increase by about $37 \%$ (of the static loading) for the elastic rock mass, whereas the same has been increased by about $51 \%$ for the elastic-perfectly plastic rock mass. This shows the significant increase of load on the support system due to the dynamic force by earthquake, in the case of weak rocks (elastic - perfectly plastic) in comparison with competent rock mass (elastic).

- The studies carried out for examining the influence of size of tunnels on the force generated in the lining due to earthquake loading, shows that there is no significant variation in the percentage increase in maximum axial force in the case of elastic rock, when tunnel dia. increased from $5.0 \mathrm{~m}$ to $10.0 \mathrm{~m}$. However, for elastic plastic rock, there is $44 \%$ to $51 \%$ increase in the maximum axial force, when the tunnel dia. is increased from $5.0 \mathrm{~m}$ to $10.0 \mathrm{~m}$. Also the increase in maximum axial force is significant under earthquake loading condition in the case of elastic - plastic rock type.

- The maximum axial force due to seismic load increased by twice in the case of very poor rock $(Q=0.55)$ while there is no increase in the case of $\operatorname{good} \operatorname{rock}(\mathrm{Q}=25)$. When both the static and seismic loading is considered, the change in maximum axial force is from $0.24 \mathrm{MN}$ to $0.35 \mathrm{MN}$ (1.4 times) for good rock and from $0.82 \mathrm{MN}$ to $2.11 \mathrm{MN}$ (2.6 times) in the case of very poor rock. This clearly shows that the impact of seismic loading is significant in the case of poor and very poor rock than for good rock mass.

- The rock mass parameters, the stress - strain behavior of rock mass, whether it is elastic or elastic-plastic, the size of excavation, depth of excavation below ground and 
seismic coefficients ( horizontal \& vertical) significantly influence the results of the study. Hence determination of these parameters as realistic as possible is very important. The parameters adopted in the study are assumed and hence the maximum axial force in the lining and the percentage increases are only indicative. These may vary depending on the actual situations.

- The increase in axial force in the rock support / lining due to seismic loads also matches well with the approximation, Q (seismic) $=(1 / 2) \times \mathrm{Q}$ (static) as suggested by Nick Barton, in the paper published in 1984 for design of rock support on the basis of Qsystem.

- Further studies are necessary for analyzing the impact of seismic loading on rock bolts, cable anchors etc. and also on large caverns (power house, transformer hall etc.) located at different depths.

\section{REFERENCES}

[1] Rajinder Bhasin , Kaare Hoeg and Mostafa Abokhalil, "Effect of seismicity on rock support in tunnels", World Tunnel Congress 2008.

[2] Fereydoon Amanloo and Vahid Hosseinitoudeshki, "The Effect of Seismic Load on the Displacement of Tunnel in the Jointed Rock Masses" Middle-East Journal of Scientific Research 17 (2): 137-141, 2013.

[3] Rajinder Bhasin, "Effect of earthquake on rock support in tunnels", Tunnelling Asia 2013, New Delhi.

[4] Giuseppe Maria Gaspari, Giovanni Quaglio and Vincenza Floria "Simplified numerical method for tunnel design under seismic condition: Some examples about Istanbul Metro design, KadikoyKartal Line" Geotechnical Aspects of Underground Construction in Soft Ground.

[5] Navid Hosseini, Kazem Oraee, Mehran Gholinejad, "Seismic analysis of horseshoe tunnels under dynamic loads due to earthquakes", Coal Operators' Conference, University of Wollongong.

[6] Rocscience Inc.. Phase2 Program reference Manual. 